\title{
Standardising approaches to food and fluid monitoring across Wales
}

\author{
J. Jenkins ${ }^{1}$ and D. Richards ${ }^{2}$ \\ ${ }^{1}$ Department of Nutrition and Dietetics, Cardiff and Vale University Local Health Board, UHW, Cardiff, CF14 4XW, UK \\ and ${ }^{2}$ Department for Public Health and Health Professions, Welsh Assembly Government, Cathays Park, \\ Cardiff CF10 $3 N Q, U K$
}

The Welsh Assembly Government's (WAG) 'One Wales' commitment is to improve hospital food and patient nutrition ${ }^{(1)}$. The Minister of Health and Social Services formally launched the report 'Free to Lead, Free to Care, Empowering Ward Sisters/Charge Nurses' in June $2008^{(2)}$. Final recommendations of this report included the need for development of a national nutritional care pathway and all-Wales food and fluid balance charts.

Underpinning the nutritional care pathway are the activities of nutritional risk screening; monitoring food and fluid intake and output; and to protect mealtimes to maximise the opportunity for nutritional intake.

The practice of recording food and fluid intake on inpatient wards is a localised and subjective activity. Recording is sporadic and not always accurate. This scenario has arisen as a result of a lack of clearly articulated standards and guidance for nursing and allied professionals.

A month long audit of newly developed draft all-Wales food charts and existing all-Wales fluid balance chart was undertaken in December 2008 with 5 NHS Trusts participating. This allowed a review of practices at the ward level to be undertaken and a user evaluation of proposed resources to take place.

Two types of photographic posters for fluid and food were provided for display on participating wards. These acted as a visual standard for recording amounts and volumes, along with instructions on how to complete the charts.

The sample size was set for 200. One hundred and seventy five completed food charts and 102 fluid balance charts were returned. Key audit results of both charts were omissions in patient identification. Recording of amounts of food and fluid ingested worsened during the day, with approximately $50 \%$ only recording fluid drunk mid-morning, lunch, mid-afternoon and dinner. Only $20 \%$ of food charts identified the time period for monitoring, $62 \%$ had no identified requestor. Of the fluid balance charts, only $57 \%$ had fluid input totalled, $46 \%$ had output totalled and $9 \%$ had a calculated fluid balance calculated. Of these, one-third miscalculated the result.

Audit data confirmed assumptions regarding practice such as incomplete and inaccurate recording. User and patient evaluation endorsed the visual guides as a good learning tool for staff and patients. Feedback from the audit has resulted in the following evidence based changes in readiness for roll out across Wales: amendments to the draft food chart; redesign of the existing daily and weekly fluid balance chart; production of laminated posters and pictorial guides for hospital beds; development of an e-learning package for healthcare staff and integration into the NHS core learning package for nurse education.

These results and proposed changes represent a major milestone in an ongoing multi-disciplinary programme of quality improvement uniting legislative departments, healthcare organisations and operational staff to improve patient nutrition.

1. Welsh Assembly Government (2007) One Wales, A Progressive Agenda for the Government of Wales.

2. Welsh Assembly Government (2008) Free to Lead, Free to Care. Empowering Ward Sisters/Charge Nurses Ministerial Task and Finish Group. 